\title{
EMPRESAS LISTADAS NA B3 VS. PROCESSOS SANCIONADORES DA CVM: EM QUAL SETOR VOCÊ APOSTA?
}

\section{COMPANIES LISTED IN B3 VS. CVM SANCTION PROCESSES:" IN WHICH INDUSTRY DO YOU BET?}

O artigo foi aprovado e apresentado no II Congresso UFU de Contabilidade, realizado de 19 e 20/10 de 2017, em Uberlândia (MG).

\begin{abstract}
RESUMO
Este estudo busca identificar como as empresas listadas na B3 (Brasil, Bolsa e Balcão), separadas por setores, se caracterizam em relação aos processos administrativos sancionadores da Comissão de Valores Mobiliários (CVM). Para tanto, uma amostra de 777 processos administrativos sancionadores da CVM, do período compreendido de 1989 a 2016, foi analisada por meio da utilização da técnica estatística de Análise de Correspondência (ANACOR), agrupando, duas a duas, as seguintes variáveis: setores, segmentos, tipos de processos, tipos de penalidades e períodos de ocorrência dos processos. Os resultados apontam que, em geral, o setor Financeiro apresenta a maior quantidade de processos sancionadores administrativos. Todavia, cada setor e segmento da B3 têm características diferentes em cada um dos tipos de processos analisados, bem como em relação às penalidades imputadas após julgamento, sendo as multas, quanto às sanções, as penalidades mais aplicadas pela CVM. Os resultados alcançados por meio das particularidades setoriais encontradas possibilitam ampliar as discussões sobre a importância do papel do órgão regulador, especialmente, da CVM, quanto à atuação sobre crimes e demais ilegalidades corporativas no mercado de valores mobiliários, cujo intuito é o de melhorar a qualidade e a transparência da informação para os seus diversos stakeholders.
\end{abstract}

Palavras-chave: Processos sancionadores da CVM; ilegalidades no mercado de valores mobiliários; abordagem setorial; análise de correspondência; sanções da CVM.

\begin{abstract}
This study seeks to identify how the companies listed in B3 (Brazil, Stock Exchange and Counter), separated by industries, characterized in relation to the administrative sanctions processes of the Securities Commission (CVM). Therefore, a sample of 777 CVM administrative sanctioning processes were analyzed from 1989 to 2016 using the statistical technique of Correspondence Analysis (ANACOR) combination of following variables two to two: industries, segments, types of processes, types of penalties and periods of occurrence of the processes. The results indicate that, in general, the Financial Industry presents the highest amount of administrative sanctioning processes. However, each industry and segment of B3 has different characteristics for each type's processes analyzed, as well as for penalties received after judgment. And, finally, regarding penalties, fines are the penalties most applied by the CVM. The results achieved through the industrial particularities found make it possible to broaden the discussions about the importance of the role of the regulatory organ especially the CVM, in relation to its actions on crimes and other corporate illegalities on the securities market, with the aim of improving the quality and transparency of information for its for its several stakeholders.
\end{abstract}

Keywords: CVM sanction processes; illegalities on the securities market; industrial approach; correspondence analysis; CVM sanctions.

\section{Sabrina Rafaela Pereira Borges}

Mestre em Ciências Contábeis pela Universidade Federal de Uberlândia. Graduada em Administração pela Universidade Federal de Uberlândia. Docente no curso de graduação em Ciências Contábeis na Universidade Federal de Uberlândia. Contato: Av. João Naves de Ávila, n 2121 - 1F - Sala 205, Bairro Santa Mônica, CEP 38400-902, E-mail: sabrinarpb@yahoo.com.br.
Maria Elisabeth Moreira Carvalho Andrade
Doutora em Ciências Contábeis pela faculdade de Economia, Administração e Contabilidade de São Paulo. Mestre em Controladoria e Contabilidade pela Faculdade de Economia, Administração e Contabilidade de Ribeirão Preto da Universidade de São Paulo. Graduada em Ciências Contábeis pela Faculdade de Ciências Econômicas do Triângulo Mineiro. Docente no curso de Ciências Contábeis (graduação e pós-graduação) na Universidade Federal de Uberlândia. Contato: Av. João Naves de Ávila, $n^{\circ}$ 2121 - Bloco 1F - Sala 205, Bairro Santa Mônica, CEP 38400-902, E-mail: maria.elisabeth@ufu.br. 


\section{INTRODUÇÃO}

Martins, Miranda e Diniz (2014) asseveram que a Contabilidade deve ser compreendida como um modelo de representação da situação econômico-financeira de uma organização. Sendo assim, o objetivo da Contabilidade é fornecer informações úteis, confiáveis, verificáveis, comparáveis e transparentes de modo a auxiliar os seus diversos usuários na tomada de decisões (IUDÍCIBUS; MARION; FARIA, 2009). Entretanto, Murcia e Santos (2009) explicam que vários estudos têm apontado um baixo nível de evidenciação contábil nas empresas brasileiras. Assim sendo, a Contabilidade tem sido constantemente alvo de notícias de escândalos associados à manipulação contábil, trazendo prejuízos para investidores e demais usuários externos (HENRIQUE, 2016).

Nesse sentido, Girão e Machado (2013) destacam o problema da assimetria informacional, sendo evidente o conflito de interesse que existe entre o principal e o agente, em que o principal toma decisões de cunho pessoal que conflitam com a maximização de riqueza da entidade e dos acionistas diante do maior acesso às informações que não estão disponibilizadas ao mercado. Assim, é em virtude da existência desse conflito de interesses que os gestores se aproveitam das brechas presentes na legislação para atingirem os seus objetivos pessoais (MURCIA; SANTOS, 2009).

Desse modo, há a necessidade de intervenção de um agente regulador que, por meio dos regulamentos e normas, possa garantir que as informações contábeis divulgadas não apresentem erros e/ou vieses (BEAVER, 1998). Nesse sentido, ganha importância a Comissão de Valores Mobiliários (CVM) como um órgão regulador e fiscalizador no Brasil que é responsável por normatizar e controlar o mercado de valores mobiliários (ASSAF NETO, 2010). Uma das funções desempenhadas pela CVM diz respeito aos denominados processos sancionadores administrativos, pelos quais a CVM impõe sanções às pessoas físicas e jurídicas que "praticam atos qualificados em lei ou como ilícitos administrativos" (MEDAUAR, 1993, p. 115). Portanto, entende-se por processos administrativos sancionadores as ações ilegais praticadas por administradores, acionistas, membros de conselho fiscal, intermediários e demais públicos que participam do mercado de valores mobiliários (CVM, 2008; SMETANA, 2015).

Beasley et al. (2000) destacam a importância de se considerar o setor para a análise das irregularidades contábeis e a compreensão de suas particularidades, uma vez que a análise setorial tem demonstrado peculiaridades em processos sancionadores, bem como outras irregularidades contábeis e não contábeis (SMETANA, 2015). Diante do exposto, busca-se nesta pesquisa responder a seguinte questão: Como os setores da B3 se caracterizam em relação aos processos administrativos sancionadores da CVM? Assim, o objetivo geral desta pesquisa é identificar como as empresas listadas na B3, separadas por setores, se caracterizam em relação aos processos sancionadores da CVM. Mais especificamente, os propósitos desta pesquisa são: (i) verificar a associação entre os setores da B3 com os tipos de processos sancionadores da CVM; (ii) analisar a associação entre os tipos de processos sancionadores e os tipos de penalidades aplicadas pela CVM, bem como o período do fato ocorrido; e (iii) averiguar a relação entre os setores da B3 e as empresas que estão em recuperação judicial, bem como os tipos de processos sancionadores das mesmas.

Apesar da atuação da auditoria e da fiscalização exercida pela CVM, as empresas omitem e divulgam informações distorcidas, o que justifica a existência dos processos sancionadores e os pedidos de refazimento das demonstrações contábeis (FONTES, 2013). Assim sendo, a fiscalização e as punições aplicadas pela CVM são importantes para que as empresas cumpram as regras necessárias e, assim, as relações entre elas e seus stakeholders tenham transparência e qualidade (COSTA, 2012). Logo, diante do número de fraudes contábeis e outros atos ilícitos nos últimos anos, torna-se importante compreender em quais aspectos as empresas cometem falhas e quais são as devidas punições a elas aplicadas.

De modo geral, esta pesquisa contribui em termos teóricos e práticos. Em termos teóricos, este estudo contribui ao complementar a literatura sobre a abordagem setorial com a análise dos processos sancionadores, uma vez que se têm poucas pesquisas nacionais que tratem sobre a temática com um enfoque setorial. No que tange às contribuições práticas, os resultados alcançados por meio das particularidades setoriais encontradas possibilitam ampliar as discussões sobre a importância do papel do órgão regulador no mercado de valores mobiliários, especialmente, da CVM, quanto à atuação diante de crimes e demais ilegalidades corporativas com o intuito de melhorar a qualidade e a transparência da informação para os seus diversos stakeholders, bem como quanto à aplicação mais eficaz de sanções diante das irregularidades no mercado mobiliário, cujos aspectos são ressaltados por Beaver (1998) e Costa (2012). Além disso, esta pesquisa contribui para a compreensão das especificidades setoriais.

\section{REVISÃO DA LITERATURA}

\subsection{A Importância do Órgão Regulador para as Irregularidades Contábeis}

Nem todos os stakeholders recebem a mesma quantidade e qualidade de informação, ou seja, há sempre heterogeneidade nas informações recebidas pelos usuários externos de uma organização, o que leva à ocorrência da assimetria informacional (BEAVER, 1998; ZIMMERMAN, 2015). Assim, a informação assimétrica representa a diferença de informação existente em uma relação contratual entre o agente e o principal, pelo fato de uma das partes deter um maior nível de informação (JENSEN; MECKLING, 1976; BROWN; HILLEGEIST, 2005).

Girão e Machado (2013) estudaram sobre a problemática da assimetria informacional em um contexto internacional, demonstrando que a existência da assimetria informacional é o principal aspecto responsável pelo surgimento da oportunidade para o indivíduo cometer um ato em benefício próprio e trazer danos a terceiros. Logo, a assimetria 
informacional é o que reforça a importância e a necessidade de existência da Contabilidade e da própria regulação contábil (BEAVER, 1998).

Sendo assim, a necessidade de corrigir falhas de mercado é o que justifica a existência da regulação, bem como a necessidade de informações contábeis cada vez mais claras e acessíveis a todos os interessados (SCHIPPER, 2003; SCOTT, 2014. Contudo, a assimetria informacional é um dos maiores problemas enfrentados pelos agentes reguladores, uma vez que esses necessitam de informações minuciosas sobre as atividades econômico-financeiras e operacionais das entidades (KOTHARI; RAMANNA; SKINNER, 2010).

No Brasil, a regulação e a fiscalização do mercado de valores mobiliários têm sido de responsabilidade da CVM (DANTAS et al. 2011). A CVM é uma autarquia federal vinculada ao Ministério da Fazenda e foi instituída pela Lei $n^{\circ}$ 6.385, de 07 de dezembro de 1976, com a finalidade de disciplinar, fiscalizar e desenvolver o mercado de valores mobiliários (BRASIL, 1976). Quanto à fiscalização, a CVM tem o papel de acompanhar as informações veiculadas no mercado mobiliário e os indivíduos que dele fazem parte. Já como órgão regulador, o papel da CVM envolve disciplinar e fiscalizar o mercado de valores mobiliários, punindo aqueles que descumprem as regras constituídas (PORTAL BRASIL, 2017). Logo, cabe à CVM corrigir as falhas no mercado imobiliário e promover aplicações de sanções administrativas aos infratores por meio de processos administrativos (METO et al. 2017).

O fato é que a regulação no mercado de valores mobiliários está relacionada com a produção e a divulgação de informações e os diversos escândalos ocorridos ao longo do tempo fizeram com que aumentasse a importância da regulação como proteção aos investidores (SCOTT, 2014).

Nesse sentido, as companhias abertas, empresas de auditoria, corretoras de valores mobiliários, agentes autônomos de investimento, fundos de investimento e administradores de carteira estão submetidos à autoridade da CVM. Assim, cabe à CVM interferir sempre que uma empresa de capital aberto emitir uma informação enviesada sobre a sua posição patrimonial om vistas a manter a credibilidade nos relatórios publicados pelas companhias (EIZIRIK, 2008; FUSIGER; SILVA; CARRARO, 2015).

Dessa forma, assim como os órgãos reguladores têm um importante papel em garantir a qualidade da informação contábil, o acesso a essa informação também é importante para esses órgãos, pois é por meio dela que os órgãos reguladores poderão tomar devidas providências com o intuito de instigar a firma regulada a operar de forma eficiente (KOTHARI; RAMANNA; SKINNER, 2010).

Historicamente, a regulação tem passado por mudanças frente às transformações dos setores econômicos e às complexidades dos negócios, bem como em virtude do comportamento dos diversos agentes envolvidos no processo regulatório (SCHIPPER, 2003). Destarte, a intensa concorrência nos mercados devido à globalização tem levado as empresas a recorrerem às irregularidades contábeis com vistas a obterem um melhor desempenho e a se manterem competitivas. É nesse contexto que surge a importância da atuação dos órgãos reguladores para banir as possíveis irregularidades contábeis (KOTHARI; RAMANNA; SKINNER, 2010).

\subsection{Processos Administrativos Sancionadores}

Nos Estados Unidos, a Security and Exchange Commission (SEC) emite, desde 1982, a Accounting and Auditing Enforcement Releases (AAERs) que indica vários processos associados à má conduta contábil, apresentando a natureza das ações e o impacto ocorrido nas demonstrações contábeis. Na China, a China Stock Market and Accounting Research Database (CSMAR) apresenta processos relacionados à violação de provisões de fundos por parte dos acionistas, atividades de expropriação e aquisição de ações ilegais ou manipulação de preços de ações, fraudes de demonstrativos financeiros e atrasos nos envio de informações periódicas. Diante disso, a SEC e a CSMAR adotam ações de execução contra as empresas, executivos, auditores e outras partes que estejam envolvidas nas violações das regras vigentes (DECHOW et al. 2007; LISIC et al. 2015).

Assim como a SEC, nos Estados Unidos, e a CSMAR, na China, a CVM regula e controla o mercado acionário no Brasil. A Lei $n^{\circ} 6.385$ determina que a CVM tem a responsabilidade de apurar, julgar e punir as irregularidades que são cometidas no mercado financeiro do país (BRASIL, 1976). Ainda, em 1999, foi editada a Lei $\mathrm{n}^{\circ} 9.784$ que regula o processo administrativo sancionador, definindo que tais processos são de competência da CVM e do Conselho de Recursos do Sistema Financeiro Nacional (CRSFN) (BRASIL, 1999).

Há dois tipos de procedimentos nos processos administrativos sancionadores na esfera da CVM: o procedimento por rito ordinário e o procedimento por rito sumário. A diferença dos procedimentos por ritos sumários e ordinários está no prazo e no valor da penalidade aplicada. Os processos por ritos sumários têm prazos menores de resoluções, multas menores e referem-se às infrações consideradas objetivas, enquanto que os processos por rito ordinários têm prazos maiores de julgamento e penalidades com multas de até $\mathrm{R} \$ 500$ mil (CVM, 2014).

As sanções administrativas aplicadas pela CVM são classificadas como de menor gravidade ou graves (COELHO, 2004). A absolvição, a advertência e a multa são exemplos de penalidades de menor gravidade, enquanto que a suspensão do exercício de cargo, a inabilitação para o exercício do cargo temporariamente, a suspensão de autorização ou do registro para o exercício de atividades, a cassação de autorização ou do registro para o exercício ou atividades, a proibição para a prática de atividades ou de operações, bem como a proibição de atuar em determinadas operações de mercado são exemplos de penalidades graves. Todas essas penalidades são definidas pelo Art. 11 da Lei $\mathrm{n}^{\circ}$ 9.457/97, Art. 11 da Lei $n^{\circ}$ 6.385/76 e Art. 130 da Lei $n^{\circ}$ 8.112/90 (BRASIL, 1997). 
A proibição temporária se dá em um período máximo de 20 anos, ficando o infrator impedido de realizar certos tipos de operações no mercado, entretanto o infrator não tem a cassação da autorização ou do registro da entidade, o que permite que outras atividades possam ser realizadas normalmente. Já a inabilitação impede o infrator, por um período de 20 anos, de exercer sua atividade em qualquer entidade submetida à jurisdição da CVM e tem sido aplicada, principalmente, aos administradores das corretoras (EIZIRIK et al. 2008). Destaca-se que a multa aplicada pela CVM não pode exceder aos seguintes valores: $\mathrm{R} \$ 500.000,00$; cinquenta por cento do valor da emissão ou da operação irregular; ou, ainda, três vezes o valor da vantagem obtida ou da perda evitada em decorrência do ato ilícito (BRASIL, 1997).

Cabe destacar que as sanções aplicadas podem ser substituídas pelos Termos de Ajustamento de Conduta na esfera administrativa, segundo os quais negociações entre as partes permitem que um processo administrativo possa ser evitado ou encerrado (SUNDFELD; CÂMERA, 2011). A título de exemplificação, Sundfeld e Câmera (2011) discorrem sobre o contexto dos acordos substitutivos no setor de telecomunicações. Considera-se oportuno esclarecer que os Termos de Ajustamento de Conduta não se enquadram no escopo da presente pesquisa.

As pesquisas correlatas em relação à temática de processos sancionadores envolvem os estudos de Dechow et al. (2007), Camargos, Romero e Barbosa (2008), Cunha (2009), Costa (2012), Farias, Freitas e Vicente (2015), Fusiger, Silva e Carraro (2015), Smetana (2015), Silva (2015) e, mais recentemente, de Melo et al. (2017) e Oliveira (2017).

Dechow et al. (2007) analisaram as características das empresas que foram objeto de ações de execução, tanto no ano da manipulação, quanto nos anos anteriores. Os autores concluíram que as manipulações aconteciam com maior frequência em empresas que estavam em crescimento. Por sua vez, Cunha (2009) analisou os processos administrativos sancionadores associados às práticas não equitativas no mercado de capitais e a respectiva penalidade aplicada pela CVM, concluindo que as práticas não equitativas mais adotadas pelos agentes que atuam no mercado são: registrar ordens de compra e venda de forma incorreta; realizar negociações fora do ambiente regulado; obter conhecimento antecipado de compras que serão realizadas; e realizar negócios, visando ao lucro para terceiro. Ressalta-se que a multa tem sido a sanção mais aplicada para o processo sancionador associado à prática não equitativa.

Costa (2012) analisou dois processos administrativos sancionadores da CVM relacionados à auditoria, especialmente, os que tangem aos erros e fraudes. $\mathrm{O}$ autor concluiu que o parecer de auditoria sem ressalva era o tipo de processo sancionador mais frequente e a multa ou a suspensão das atividades praticadas eram as penalidades mais aplicadas para esse tipo de processo sancionador. Fusiger, Silva e Carraro (2015) também analisam o processo sancionador administrativo a respeito de irregularidades cometidas pelos auditores independentes, pessoas físicas e jurídicas. A conclusão dos autores apontou que a existência de relatórios impróprios, a não execução ou ausência de procedimentos de auditoria e de registros do auditor são as principais irregularidades associadas a esse tipo de processo sancionador na CVM. Silva (2015) estudou as infrações dos auditores independentes em processos administrativos sancionadores no período de 2000 a 2014, apresentando como resultados que as penalizações em forma de multa, advertência e suspensão do registro foram as mais aplicadas nesses tipos de irregularidades.

Farias, Freitas e Vicente (2015) fizeram um estudo sobre o insider trading, encontrando 39 processos administrativos sancionadores na CVM atrelados ao acesso à informação privilegiada. Os autores ainda evidenciaram que a penalidade em forma de multas tem sido mais aplicada como sanção para processos dessa natureza. Oliveira (2017) também estudaram sobre o insider trading, porém sob o enfoque das práticas de governança corporativa das empresas envolvidas nesse tipo de processo na CVM, não encontrando relação entre os níveis de governança corporativa das empresas com os processos analisados sobre insider trading.

Camargos, Romero e Barbosa (2008) estudaram a relação entre os processos administrativos ordinários e a área de Compliance, no período de 2000 a 2004, apresentando evidências de retornos anormais para os acionistas diante de casos de informação privilegiada em negociações de fusões e aquisições. Smetana (2015) também estudou a relação da Compliance e as empresas envolvidas nos processos administrativos sancionadores da CVM, chegando à conclusão que as empresas que possuem Compliance apresentam menores níveis de incidência em processos administrativos.

E, por último, Melo et al. (2017) analisaram a qualidade da informação contábil e o papel de atuação da CVM por meio dos processos administrativos sancionadores, concluindo que a CVM considera como infração grave os aspectos associados à má qualidade da informação contábil. Contudo, de modo geral, na literatura nacional, há apenas estudos incipientes que tratam sobre os processos administrativos sancionadores e nenhum, de fato, incluiu a abordagem setorial da B3.

Diante do exposto, nota-se que que poucos os estudos nacionais que relacionam a abordagem setorial com a temática de processos contábeis. No contexto internacional, Lisic et al. (2015) estudaram os setores em relação aos processos da SEC sobre fraude contábil. Os autores concluíram que os setores com maior incidência desse tipo de fraude eram os setores agrícolas e de mídias. No Brasil, apenas os estudos de Teixeira, Politelo e Klann (2013) e Cunha, Fernandes e Magro (2017) relacionaram os setores com os pedidos de refazimento da CVM, concluindo que o setor de consumo não cíclico apresenta o maior número de casos de refazimento de demonstrações contábeis. Na literatura nacional, não foi encontrado qualquer estudo que associasse a abordagem setorial com os processos administrativos sancionadores da CVM, o que justifica a importância desta pesquisa.

\section{ASPECTOS METODOLÓGICOS}

Quanto à natureza, esta pesquisa classifica-se como uma pesquisa quantitativa, a qual, segundo Lakatos e Marconi (2008), consiste em um estudo estatístico que busca determinadas características, medindo numericamente os levantamentos realizados acerca de um problema de pesquisa, o que se pretendeu neste estudo, pois, por meio da Análise de 
Correspondência (ANACOR), foram realizadas as associações entre os setores da B3 e os processos sancionadores da CVM. Já quanto aos fins, este estudo é classificado como uma pesquisa descritiva, pois, conforme leciona Gil (2008), esse tipo de pesquisa expõe características de determinada população ou de determinado fenômeno, podendo também estabelecer correlação entre variáveis e definir sua natureza. Assim, a partir dos processos administrativos sancionadores da CVM, busca-se identificar como os setores da B3 se caracterizam em relação a esses tipos de processos.

Quanto aos procedimentos, esta pesquisa é de caráter documental pelo fato de se utilizar dos ofícios publicados no site da CVM referentes aos processos sancionadores administrativos, bem como da classificação setorial disponível no site da B3. Para a investigação, utilizou-se a análise de um total de 808 processos administrativos sancionadores julgados pela CVM.

Esta pesquisa limitou-se a analisar os ofícios que tratam dos processos administrativos sancionadores no período de 1989 a 2016, que se refere ao período em que os dados foram disponibilizados no site da CVM. Destaca-se que o estudo foi realizado durante o ano de 2017, portanto, por não ter sido possível obter dados do período completo, optou-se por investigar até 2016.

Ressalta-se ainda que foram considerados apenas os processos de rito ordinário já julgados pela CVM, incluindo as decisões completas e extratos de sessão de julgamento. Cabe destacar também que os despachos não foram considerados e nem os processos sancionadores envolvendo apenas pessoas físicas, como investidores individuais e auditores independentes. Assim, do universo dos 808 processos sancionadores administrativos, 31 deles foram excluídos da amostra por envolverem investidores individuais e auditores independentes. Desse modo, a amostra final do estudo foi constituída por 777 processos administrativos sancionadores.

Ao todo, 567 empresas estavam envolvidas nos processos analisados, sendo essas Sociedades Anônimas (S/A) de capital aberto ou fechado. Para a classificação das empresas nos setores analisados, foram considerados a atividade de atuação das mesmas e o enquadramento setorial proposto pela B3 conforme os segmentos de atividades.

Quanto aos setores, utilizou-se a classificação da B3 que apresenta os setores dispostos em dez categorias, sendo eles: Bens Industriais; Consumo Cíclico; Consumo não Cíclico; Financeiro e Outros; Materiais Básicos; Petróleo, Gás e Biocombustíveis; Saúde; Tecnologia da Informação; Telecomunicações; e Utilidade Pública (B3, 2016). No entanto, dentro de cada setor, têm-se vários segmentos com suas próprias particularidades, por isso, dentro desses setores, também foi incluída a análise por segmentos como variável de análise.

O setor de Bens Industriais apresenta o segmento de Máquinas e Equipamentos como o mais representativo e algumas características principais do setor envolvem a similaridade da estrutura de ativos das empresas com uma estrutura heterogênea de dívidas entre as empresas que dele fazem parte. O setor de Consumo Cíclico apresenta o segmento de Produtos Diversos como sendo o mais representativo e é caracterizado pela presença de empresas familiares e que apresentam baixo risco de falência. O setor de Consumo não Cíclico envolve empresas voltadas à agropecuária, alimentos processados, bebidas, cosméticos e saúde e algumas de suas características envolvem a sazonalidade de produção e a dependência dos custos de commodities. Já o setor de Materiais Básicos apresenta como características os elevados custos de produção atrelados aos insumos, bem como longos períodos de maturação dos investimentos. O setor de Utilidade Pública, cujo segmento mais representativo é o de Energia Elétrica, é caracterizado pela presença predominante de empresas estatais e com elevados investimentos em equipamentos para a realização de suas atividades econômicas (CAVALCANTI; CASTRO, 2015; SILVA; SCHNORRENBERGER, 2015).

O setor de Financeiro e Outros tem demonstrado maior valor adicionado para a remuneração de capitais próprios, apesar de uma das suas particularidades contábeis ser a menor proporção de capital próprio no balanço patrimonial. O setor de Petróleo e Gás apresenta a existência de altos investimentos em ativos fixos e intangíveis como uma das suas principais particularidades. O setor de Saúde tem demonstrado maior valor adicionado para os colaboradores internos, apresentando esse setor como principais características a dependência do nível de emprego, renda e taxas de câmbio, além da necessidade constantes de inovações tecnológicas. O setor de Tecnologia da Informação tem adicionado maior parte do valor gerado para os colaboradores internos. As dívidas nas empresas desse setor têm uma pequena proporção, mas é notável que o setor venha se endividando mais expressivamente desde 2013. E, por fim, o setor de Telecomunicações apresenta altos custos fixos e requer um capital intensivo, além da sua relação de dependência com terceiros pelo fato de existirem fornecedores ou empresas terceirizadas em partes importantes do negócio (PAULA; OREIRO; BASILIO, 2013; KPMG, 2015).

A coleta dos dados da pesquisa ocorreu nos meses de janeiro e fevereiro de 2017. Posteriormente a essa etapa, os dados foram analisados por meio das técnicas de estatística descritiva e pela Análise de Correspondência Simples (ANACOR). A ANACOR é uma técnica estatística multivariada de interdependência que facilita tanto a redução dimensional da classificação de objetos em um conjunto de atributos quanto o mapeamento espacial de objetos relativos a esses atributos. Assim sendo, essa técnica estatística busca mostrar como as variáveis dispostas em linhas e colunas estão relacionadas, permitindo a criação de mapas perceptuais que facilitam a análise das associações entre duas variáveis não métricas (FÁVERO et al. 2009).

Assim, esta pesquisa buscou relacionar as seguintes variáveis qualitativas nominais: setores, segmentos, ano inicial do processo sancionador, tipos dos processos administrativos sancionadores e tipos de penalidades aplicadas pela CVM. Considerações também foram feitas quanto à situação das empresas envolvidas nos processos com vistas a evidenciar se essas se encontravam ou não em recuperação judicial. Contudo, para a variável recuperação judicial, 
não se aplicou a ANACOR devido ao fato de essa variável não atender ao pressuposto do teste quanto à quantidade mínima de dimensão. É importante destacar que foi utilizada a normalização simétrica para a aplicação da ANACOR, uma vez que, conforme apontado por Fávero et al. (2009, p. 289), há o interesse em examinar as diferenças ou similaridades entre duas variáveis simultaneamente.

Pestana e Gageiro (2014) recomendam o teste de Qui-Quadrado como primeiro passo antes de ser realizada a ANACOR com o intuito de verificar se existe dependência entre as variáveis analisadas, e, consequentemente, avaliar o quanto a ANACOR é adequada. Sendo assim, a Tabela 1 traz o resultado do teste de Qui-Quadrado de Independência para cada uma das variáveis do estudo. Como é possível perceber, cinco variáveis (Ano e Processo; Ano e Setor; Processo e Penalidade; Processo e Setor; e Setor e Penalidade) podem ser associadas, uma vez que, para todas elas, houve significância ao nível de $5 \%$, o que implica em rejeição da hipótese nula de que não há associação entre as categorias das duas variáveis do estudo, ou seja, as categorias não estão combinadas de modo aleatório, o que permite a aplicação da ANACOR. Entretanto, não é possível a aplicação da ANACOR para medir a associação entre a variável Ano e a variável Penalidade, uma vez que ambas estão combinadas de modo aleatório.

Tabela 1 - Resultado do teste de Qui-Quadrado de Independência

\begin{tabular}{c|c}
\hline Associação & P-valor \\
\hline Ano e Penalidade & 0,985 \\
Ano e Processo & 0,000 \\
Ano e Setor & 0,000 \\
Processo e Penalidade & 0,024 \\
Processo e Setor & 0,000 \\
Setor e Penalidade & 0,007 \\
\hline
\end{tabular}

Fonte: Dados da Pesquisa

\section{RESULTADOS}

Na Tabela 2, apresenta-se a quantidade de processos administrativos sancionadores em relação aos setores da B3. Ressalta-se que os processos relacionados à auditoria foram considerados como um "setor" à parte, já que o mesmo não estava inserido em qualquer um dos setores pela classificação da B3.

Tabela 2 - Quantidade de processos administrativos sancionadores em relação aos setores analisados

\begin{tabular}{c|c|c}
\hline Setor & Frequência Absoluta & Frequência Relativa \\
Auditoria & 49 & $6,31 \%$ \\
Bens Industriais & 72 & $9,27 \%$ \\
Consumo Cíclico & 74 & $9,52 \%$ \\
Consumo não Cíclico & 60 & $7,72 \%$ \\
Financeiro e Outros & 382 & $49,16 \%$ \\
Materiais Básicos & 63 & $8,11 \%$ \\
Petróleo, Gás e Biocombustíveis & 13 & $1,67 \%$ \\
Saúde & 8 & $1,03 \%$ \\
Tecnologia da Informação & 5 & $0,64 \%$ \\
Telecomunicações & 31 & $3,99 \%$ \\
Utilidade Pública & 20 & $2,57 \%$ \\
Total & 777 & $100,00 \%$ \\
\hline
\end{tabular}

Fonte: Dados da pesquisa.

Observa-se, conforme a Tabela 2, que a maioria (49,16\%) dos processos administrativos sancionadores da CVM se encontra no setor Financeiro e Outros. Os setores de Tecnologia da Informação e Saúde são os que apresentam as menores quantidades de processos sancionadores, com $0,64 \%$ e 1,03\%, respectivamente, de todos os processos analisados. Desse modo, os processos sancionadores e pedidos de refazimento da CVM parecem apresentar diferenças quanto à abordagem setorial, uma vez que, nos pedidos de refazimento, a maior ocorrência de processos tem sido no setor de Consumo não Cíclico, conforme apresentado por Teixeira, Politelo e Klann (2013) e Cunha, Fernandes e Magro (2017). 
O mapa perceptual entre os tipos de processo sancionadores administrativos e os setores é representado na Figura 1.

Figura 1 - Correspondência entre os setores e os tipos de processos administrativos sancionadores

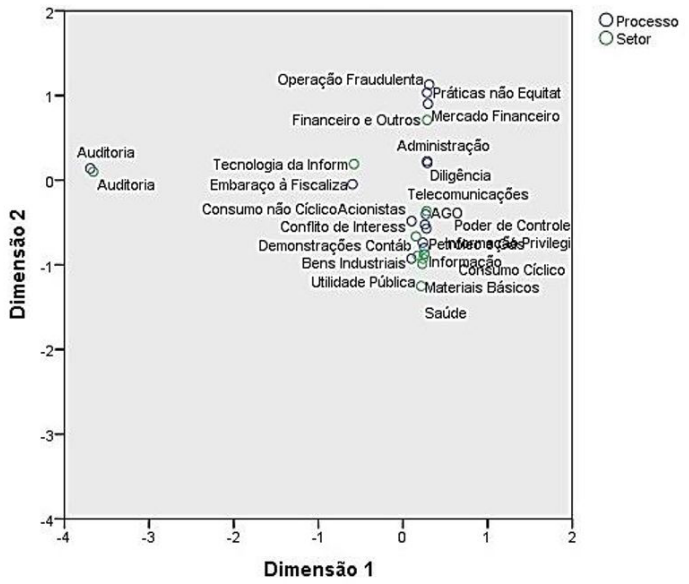

Fonte: Dados da pesquisa

Por meio da Análise de Correspondência entre os setores e os tipos processos, nota-se que o setor Financeiro apresenta processos administrativos sancionadores mais associados às operações fraudulentas, práticas não equitativas e irregularidades no mercado financeiro. Embaraços com a fiscalização da CVM parecem ser mais frequentes no setor de Tecnologia da Informação, enquanto que os setores de Materiais Básicos e Consumo Cíclico apresentam mais processos relacionados à ocultação de informações ou não divulgação de fatos relevantes. Diferentemente dos achados de Lisic et al. (2015), o setor de Consumo não Cíclico tem apresentado mais processos sancionadores no que tange à obtenção de vantagem indevida e irregularidades cometidas contra acionistas e não processos atrelados à fraude contábil. E, por fim, processos relativos às irregularidades nas demonstrações contábeis apresentaram maior incidência no setor de Bens Industriais.

A Figura 2 apresenta a quantidade de processos administrativos sancionadores da CVM ao longo do período analisado, que é de 1989 a 2016, sendo possível notar uma queda na quantidade desses processos. Todavia, a maior quantidade de processos envolve o período de 1999 a 2003, com uma média de 58 processos.

Em seguida, a Tabela 3 apresenta os principais tipos de processos administrativos sancionadores da CVM. Como se percebe, as irregularidades no mercado financeiro de valores mobiliários, a ocultação de informações e/ou não divulgação devida de fato relevante e as irregularidades associadas às demonstrações financeiras são os tipos de processos administrativos sancionadores mais comuns, representando, em conjunto, cerca de $40 \%$ de todos os processos sancionadores da CVM. Por outro lado, os processos relacionados ao embaraço à fiscalização da CVM, irregularidades com acionistas e obtenção de vantagem indevida são os tipos de processos sancionadores com menor frequência de ocorrência, o que contradiz os resultados da pesquisa de Costa (2012). Ressalta-se que alguns processos sancionadores se referiam a mais de um tipo de processo e as classificações dos processos descritas na Tabela 3 foram de elaboração própria desta pesquisadora a partir do conteúdo dos processos contidos no resumo dos processos analisados.

Figura 2 - Quantidade de processos administrativos sancionadores em relação ao período analisado

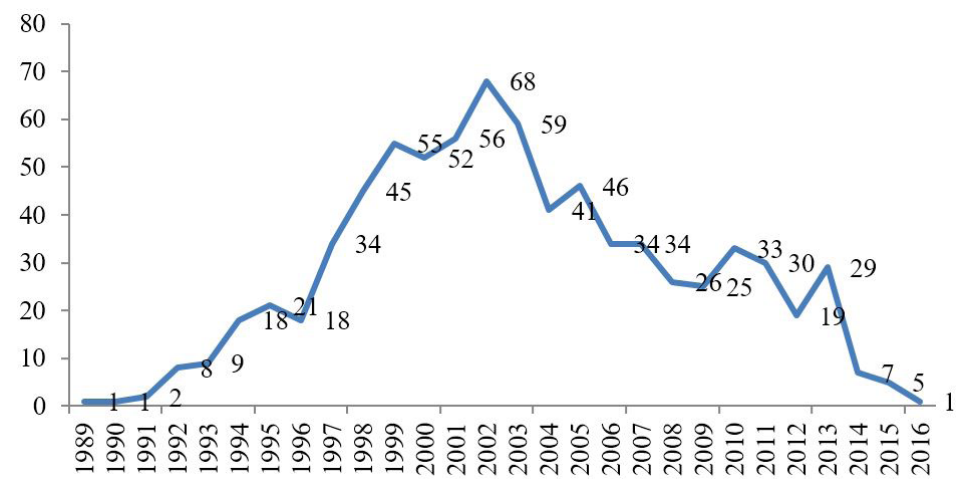

Fonte: Dados da pesquisa. 
Tabela 3 - Tipos de processos administrativos sancionadores

\begin{tabular}{|c|c|c|}
\hline Tipo de Processo & $\begin{array}{l}\text { Frequência } \\
\text { Absoluta }\end{array}$ & $\begin{array}{l}\text { Frequência } \\
\text { Relativa }\end{array}$ \\
\hline Abuso do poder de controle & 66 & $4,81 \%$ \\
\hline Embaraço à fiscalização da CVM & 18 & $1,31 \%$ \\
\hline Informação privilegiada & 51 & $3,71 \%$ \\
\hline Irregularidades com acionistas & 40 & $2,91 \%$ \\
\hline Irregularidades envolvendo auditoria & 61 & $4,44 \%$ \\
\hline Irregularidades nas demonstrações financeiras/Contabilidade & 148 & $10,78 \%$ \\
\hline Irregularidades no mercado financeiro de valores mobiliários & 222 & $16,17 \%$ \\
\hline Irregularidades operacionais & 96 & $6,99 \%$ \\
\hline Não cumprimento ao dever de diligência e lealdade & 124 & $9,03 \%$ \\
\hline Não manutenção do registro de companhia aberta atualizado & 73 & $5,32 \%$ \\
\hline Não realização de Assembleia Geral Ordinária (AGO) & 96 & $6,99 \%$ \\
\hline Obtenção de vantagem indevida/conflito de interesse & 41 & $2,99 \%$ \\
\hline $\begin{array}{l}\text { Ocultação de informações/informações incompletas ou incorretas/não divulgação ou atraso } \\
\text { na divulgação de fato relevante }\end{array}$ & 181 & $13,18 \%$ \\
\hline Operação fraudulenta & 95 & $6,92 \%$ \\
\hline Práticas não equitativas & 61 & $4,44 \%$ \\
\hline Total & 1373 & $100,00 \%$ \\
\hline
\end{tabular}

Fonte: Dados da pesquisa.

Ainda conforme mostra a Tabela 3, os processos relacionados ao abuso de poder de controle, irregularidades com acionistas, obtenção de vantagem indevida e práticas não equitativas têm relação com o conflito de agência apresentado por Brown e Hillegeist (2005). Já os processos associados à operação fraudulenta, ocultação de informações, informações incompletas ou incorretas, não divulgação ou atraso na divulgação de fato relevante e informação privilegiada têm relação com a discussão da assimetria informacional discutida por Girão e Machado (2013). Ressalta-se que o tipo de processo relativo ao acesso às informações privilegiadas também foram levantados nos trabalhos de Farias, Freitas e Vicente (2015) e Oliveira (2017) como possivelmente relacionado à assimetria informacional.

De acordo com as práticas não equitativas apontadas por Cunha (2009), foram encontrados, nos processos sancionadores, aquelas que envolvem a realização de negociações fora do ambiente regulado e realização de negócios visando ao lucro de terceiros. O fato é que todas as 1.373 irregularidades encontradas nos 777 processos analisados corroboram com a discussão da baixa evidenciação e pouca transparência da informação aos diversos stakeholders de uma organização, como exposto por Murcia e Santos (2009) e Henrique (2016).

Abaixo, a Figura 3 apresenta a relação entre os tipos de processos e períodos analisados. Observa-se que os processos administrativos sancionadores relacionados ao abuso do poder de controle e irregularidades com acionistas apresentaram maior ocorrência no ano de 1998. Já no ano de 1999, as operações fraudulentas, práticas não equitativas, irregularidades nas demonstrações contábeis e o não cumprimento do dever de diligência e lealdade foram os processos sancionadores mais frequentes. Além disso, a obtenção de vantagem indevida foi o processo com maior nível de incidência no período de 2000 . 
Figura 3 - Correspondência entre os tipos de processos administrativos sancionadores e os períodos de 1989 a 2016

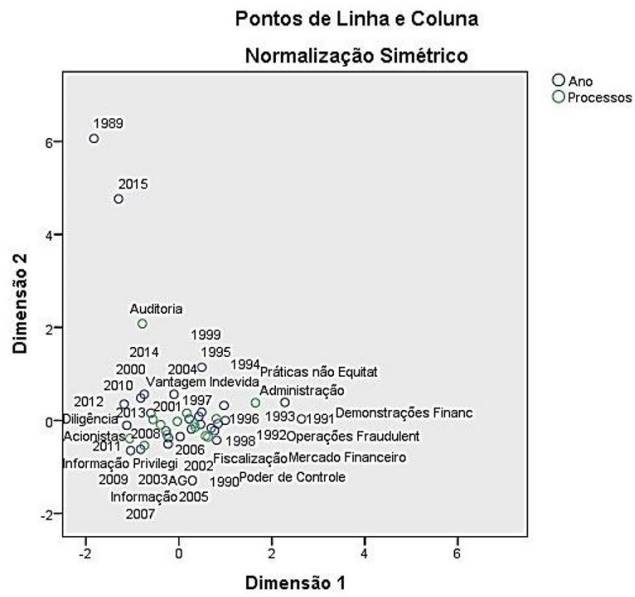

Fonte: Dados da pesquisa

Ainda a respeito da Figura 3, nota-se que os processos de embaraço à fiscalização da CVM e a não realização de Assembleia Geral Ordinária foram mais evidentes no período de 2002. Já as irregularidades no mercado financeiro de valores mobiliários ocorrem com maior frequência nos anos de 2001 e 2002. Nos anos de 2002 e 2003, ocorreram muitos processos associados às irregularidades operacionais e ocultação de informações, não divulgação ou atraso na divulgação de fato relevante. Já os períodos de 1999, 2004 e 2005 apresentam maior ocorrência de processos associados ao não cumprimento do dever de diligência e lealdade. Por sua vez, o período de 2007 anotou maiores números de processos associados à informação privilegiada.

E, por último, irregularidades envolvendo auditoria ocorreram com maior frequência em 2015. Mais recentemente, em 2016, a correspondência esteve associada com processos de irregularidades no mercado financeiro de valores mobiliários. Em suma, percebeu-se que, no período de 1989 a 2016, um dos segmentos do setor Financeiro, pelo menos, foi objeto de algum processo sancionador administrativo.

A partir da análise de correspondência entre os segmentos e os tipos de processos, observou-se que os processos relacionados à informação privilegiada puderam ser verificados, principalmente, nos segmentos de Equipamentos, Papel e Celulose, Carnes e Derivados e Tecidos, Vestuários e Calçados. A ocultação de informações e não divulgação ou atraso na divulgação de fato relevante foram processos que ocorreram, especialmente, nos segmentos de Serviços Médico-Hospitalares, Minerais Metálicos, Minerais não Metálicos, Bancos, Alimentos Diversos, Edificações, Hotelaria, Calçados, Máquinas e Equipamentos para Construção Agrícola e Transporte Aéreo.

Os processos sancionadores associados à obtenção de vantagem indevida estiveram presentes, sobretudo, nos segmentos de Siderurgia e Materiais de Transporte. Já os processos relativos às irregularidades nas demonstrações financeiras se aproximam mais com os segmentos de Artefatos de Ferro e Aço, Materiais Diversos, Embalagens, Exploração de Imóveis, Holdings Diversificadas, Açúcar e Álcool, Alimentos, Construção Pesada, Engenharia Consultiva e Transporte Rodoviário. O não cumprimento ao dever de diligência e lealdade tem maior evidência nos processos sancionadores dos segmentos de Petroquímicos e Agricultura. Irregularidades com acionistas foram processos sancionadores relacionados, principalmente, aos segmentos de Fios e Tecidos e Serviços de Apoio e Armazenagem.

Os processos relativos às irregularidades operacionais estão mais presentes nos segmentos de Químicos Diversos, Securitização de Recebíveis, Acessórios, Vestuário, Material Rodoviário e Transporte Ferroviário. Já os processos ligados ao abuso do poder de controle são mais frequentes nos segmentos de Fertilizantes e Defensivos, Cervejas e Refrigerantes, Produção de Eventos e Shows, Armas e Munições e Maquinas e Equipamentos Industriais. Os processos associados às irregularidades no mercado financeiro são atribuídos aos segmentos das Corretoras e Serviços Financeiros Diversos. A não realização de Assembleia Geral Ordinária foi o processo sancionador administrativo mais frequente nos segmentos de Intermediação Imobiliária, Sociedades de Crédito e Financiamento, Produtos de Limpeza e Automóveis e Motocicletas. E, por fim, operações fraudulentas são processos sancionadores com maior ocorrência nos segmentos de Previdência e Seguros e Produtos Diversos.

A respeito das correspondências em relação às sanções, percebeu-se que as multas são as penalidades mais aplicadas pela CVM, seguidas das absolvições e absolvições e multas, cujos percentuais são, respectivamente, de 46,98\%, $18,02 \%$ e 14,03\%, enquanto que a absolvição, advertência e inabilitação, a absolvição, advertência, proibição temporária e multas, a advertência e proibição temporária, a advertência e inabilitação e inabilitação e proibição temporária são as penalidades menos aplicadas em relação aos processos sancionadores administrativos. Sendo assim, considerando a classificação apresentada por Coelho (2004) quanto à gravidade das sanções aplicadas, observa-se que a CVM tem aplicado maior número de sanções de menor gravidade nos processos sancionadores administrativos. A Figura 4 apresenta a Análise de Correspondência entre os tipos de processos e as sanções aplicadas. 
Com base no mapa perceptual exposto na Figura 4, os processos de embaraço à fiscalização da CVM estão mais associados à penalidade de proibição temporária. Processos associados à obtenção de vantagem indevida e informação privilegiada se aproximam mais das penalidades de proibições temporárias e multas. Já a penalidade apenas com multas é aplicada, principalmente, quando se trata de processos administrativos sancionadores relacionados às irregularidades no mercado financeiro e demonstrações contábeis. Logo, diferentemente dos resultados de Melo et al. (2017), a CVM não tem aplicado sanções mais graves para irregularidades associadas à qualidade da informação.

Figura 4 - Correspondência entre os tipos de processos sancionadores e as penalidades aplicadas

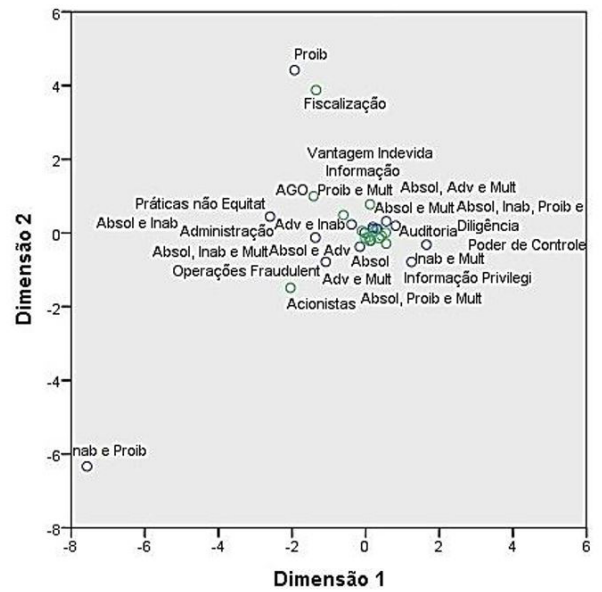

OPenalidades

Fonte: Dados da pesquisa

Além disso, absolvições foram as sanções mais aplicadas em processos relativos ao acesso de informações privilegiadas, o que vai de encontro aos estudos de Farias, Freitas e Vicente (2015). E, por fim, absolvições e inabilitações são, normalmente, aplicadas em se tratando de processos sancionadores de práticas não equitativas, o que não corrobora os achados de Cunha (2009). Por outro lado, multas e inabilitações são sanções mais aplicadas em relação a processos relacionados à auditoria, o que vai ao encontro dos resultados da pesquisa de Costa (2012) e Silva (2015).

Quanto à correspondência entre os setores e os tipos de penalidades aplicadas, notou-se que os setores Financeiro e Outros e Utilidade Pública receberam maior número de absolvições. As empresas de auditoria receberam, principalmente, advertências como sanção. Já os setores de Bens Industriais, Consumo Cíclico, Consumo não Cíclico, Materiais Básicos, Petróleo e Gás, Saúde e Telecomunicações, normalmente, receberam multas diante dos seus processos sancionadores. E, por fim, o setor de Tecnologia da Informação recebeu absolvições e, além disso, recebeu multas como principal sanção. Portanto, conforme a gravidade apresentada por Coelho (2004), todos os setores da B3 têm recebido sanções de menor gravidade.

Por meio da análise de correspondência entre os segmentos e os tipos de penalidades, nota-se que a penalidade em forma de multas foi aplicada, principalmente, nos segmentos de Medicamentos e Outros Produtos, Siderurgia, Materiais Diversos, Bancos, Produtos de Limpeza, Edificações, Fios e Tecidos, Engenharia Consultiva e Serviços de Apoio e Armazenagem. A sanção em forma de absolvição foi aplicada nos processos sancionadores, principalmente, dos segmentos de Equipamentos, Papel e Celulose, Petroquímicos, Cerveja e Refrigerantes, Tecido, Vestuário e Calçados, Serviços Educacionais e Material Rodoviário.

As penalidades conjuntas de absolvições e multas envolveram, principalmente, os segmentos de Serviços Médico-Hospitalares, Artefatos de Ferro e Aço, Corretoras, Intermediação Imobiliária, Restaurantes e Similares, Construção Pesada, Armas e Munições e Produtos para Construção. Absolvições e advertências foram sanções aplicadas, essencialmente, ao segmento de Produção de Eventos e Shows. O segmento de Minerais Metálicos recebeu sanções, principalmente, de absolvições e inabilitações. O segmento de Açúcar e Álcool foi o que mais recebeu sanções relativas à proibição temporária e multas.

Eizirik et al. (2008) discutem sobre as penalidades mais graves atribuídas pela CVM, as quais se referem à proibição temporária e inabilitação. $\mathrm{O}$ fato é que a inabilitação tem sido aplicada, geralmente, para as Corretoras no mercado de valores mobiliários. Todavia, os resultados desta pesquisa mostraram que as empresas desse segmento recebem mais pareceres atrelados às absolvições e multas.

Cabe ressaltar que, conforme apontam Kothari, Ramanna e Skinner (2010), o resultado do processo sancionador pode ser influenciado por relações políticas entre os agentes do órgão regulador e as empresas. Sendo assim, as empresas absolvidas nos processos analisados eram as mais representativas dos setores pesquisados, logo essas empresas tendem a ter maior poder político e mais recursos para praticar o lobby.

Afinal, é importante mencionar que $22 \%$ dos processos administrativos sancionadores estão associados às empre- 
sas que estão ou já estiveram em recuperação judicial. Apesar de não ter sido aplicada a ANACOR para essa variável, com base na frequência relativa, observou-se que $15 \%$ das empresas em recuperação judicial pertencem ao setor Financeiro. Ademais, essas empresas são objetos da maior quantidade de processos sancionadores sobre ocultação de informações, informações incompletas ou incorretas e não divulgação ou atraso na divulgação de fato relevante.

\section{CONSIDERAÇÕES FINAIS}

Esta pesquisa teve como propósito identificar como as empresas listadas na B3, separadas por setores, se caracterizam em relação aos processos administrativos sancionadores da CVM. Os resultados mostraram que o setor Financeiro apresenta a maior quantidade de processos sancionadores administrativos, enquanto que os setores com menores quantidades de processos dessa natureza são os de Tecnologia da Informação e Saúde.

Quanto ao propósito de verificar a associação entre os setores da B3 com os tipos de processos sancionadores da CVM, notou-se que cada setor apresenta características diferentes em relação aos tipos de processos sancionadores.

Ao analisar a associação entre os tipos de processos sancionadores e os tipos de penalidades aplicadas pela CVM, bem como o período do fato ocorrido, notou-se que a maior quantidade de processos sancionadores da CVM está associada às irregularidades no mercado financeiro, processos envolvendo erros de divulgação ou ocultação de informações e irregularidades nas demonstrações financeiras. Contudo, os tipos de processos parecem ter correspondência com o período de sua ocorrência. Entretanto, observa-se uma diminuição na quantidade de segmentos envolvidos com esses processos. O fato é que os segmentos dos diversos setores da B3 apresentam características diferentes quanto aos tipos de processos sancionadores da CVM.

No que se refere às sanções, as multas são as penalidades mais aplicadas pela CVM em se tratando de processos sancionadores. Já os processos de embaraço à fiscalização da CVM estão mais associados à penalidade de proibição temporária. Processos relativos à obtenção de vantagem indevida e informação privilegiada parecem receber mais penalidades de proibições temporárias e multas. Todavia, diferenças também foram observadas entre os setores e seus segmentos, bem como os tipos de penalidades a eles aplicadas.

Além disso, ao averiguar a relação entre os setores da B3 e as empresas que estão em recuperação judicial, bem como o tipo de processos sancionadores das mesmas, foi possível notar que $22 \%$ dos processos administrativos sancionadores estão ligados às empresas que estão ou já estiveram em recuperação judicial.

Assim, como citado na introdução, este estudo apresenta contribuições teóricas e práticas. Em termos teóricos, esta pesquisa contribui ao complementar a literatura sobre a abordagem setorial com a análise dos processos sancionadores, uma vez que se têm poucas pesquisas nacionais que tratem sobre a temática com um enfoque setorial.

No que tange às contribuições práticas, os resultados alcançados por meio das particularidades setoriais encontradas possibilitam ampliar as discussões sobre a importância do papel do órgão regulador no mercado de valores mobiliários quanto à atuação sobre crimes e demais ilegalidades corporativas com o intuito de melhorar a qualidade e a transparência da informação para os seus diversos stakeholders, cujos aspectos são ressaltados por Beaver (1998) e Costa (2012). Além disso, deve-se ter em mente que, no Brasil, o exercício da regulação ainda está em uma fase incipiente. Conforme Beasley et al. (2000) e Kothari, Ramanna e Skinner (2010) apontam, deve-se levar em consideração as mudanças nas estruturas e particularidades associadas a cada um dos setores da economia. Assim sendo, esta pesquisa ressalta a compreensão das especificidades setoriais para a aplicação das devidas sanções em virtude das irregularidades existentes no mercado de valores mobiliários.

Corroborando Farias, Freitas e Vicente (2015), este estudo enfatiza a importância da instituição de mecanismos mais assertivos e equânimes nas investigações da CVM, incluindo a contribuição de um enfoque setorial para a definição de possíveis variáveis específicas para a sua atuação enquanto órgão regulador e fiscalizador do mercado mobiliário.

A limitação desta pesquisa se deve à utilização apenas de fontes secundárias para a coleta dos dados e análise dos processos sancionadores da CVM, o que representa um retrato reducionista para a compreensão da complexidade do tema (LAKATOS; MARCONI, 2008).

Por fim, uma agenda de pesquisa é endereçada: (1) associar os achados desta pesquisa com outros processos e irregularidades contábeis, como os pedidos de refazimentos das demonstrações contábeis da CVM, ou, até mesmo, com crimes em geral, utilizando como base os processos existentes no Tribunal de Justiça de Minas Gerais, São Paulo e demais Estados do país; (2) incluir novas variáveis para análise, como, por exemplo, o tempo de resolução dos processos administrativos sancionadores até o seu julgamento final e as características das empresas envolvidas em tais processos, levando em consideração, por exemplo, a estrutura societária, as práticas de governança corporativa e o porte da empresa; e (3) incluir outros métodos de investigação com a utilização de fontes primárias, como entrevistas com órgãos reguladores sobre a temática e/ou aplicação de questionários com vistas à compreensão da opinião pública de estudantes, auditores, acionistas e a sociedade em geral quanto ao conhecimento e importância da temática que diz respeito a processos sancionadores. 


\section{REFERÊNCIAS}

ASSAF NETO, A. Mercado financeiro. 9. ed. São Paulo: Atlas, 2010.

BEASLEY, M. C.; CARCELLO, J. V.; HERMANSON, D. R.; LAPIDES, P. D. Fraudulent financial reporting: consideration of industry traits and corporate governance mechanism. Accounting Harizons, v.14, n.4, p.441-454, 2000. Disponível em: <http://dx.doi. org/10.2308/acch.2000.14.4.441>. Acesso em: 18 mar. 2017.

BEAVER, W. Financial reporting: an accounting revolution. Estados Unidos: Prentice Hall, 1998.

B3 - Brasil, Bolsa e Balcão. Empresas listadas. 2016. Disponível em: <http://www.bmfbovespa.com.br/pt_br/produtos/listados-a-vista-e-derivativos/renda-variavel/empresas-listadas.htm>. Acesso em: 21 abr. 2017.

BRASIL. Lei 6.385, de 07 de dezembro de 1976. Mercado de valores mobiliários e criação da Comissão de Valores Mobiliários. Diário Oficial [da República Federativa do Brasil], Brasília, DF, 1976.

BRASIL. Lei 9.457, de 05 de maio de 1997. Altera dispositivos da Lei n 6.385, de 7 de dezembro de 1976, que dispõe sobre o mercado de valores mobiliários e cria a Comissão de Valores Mobiliários. Diário Oficial [da República Federativa do Brasil], Brasilia, DF, 1997.

BRASIL. Lei 9.784, de 29 de janeiro de 1999. Regula o processo administrativo no âmbito da Administração Pública Federal. Diário Oficial [da República Federativa do Brasil], Brasília, DF, 1999.

BROWN, S.; HILLEGEIST, S. A. Disclosure quality and information asymmetry. Social Science Research Network, v. 12, n. 2, p. 443-477, 2005. Disponível em <doi:10.1007/s11142-007-9032-5>. Acesso em: 03 abr. 2017.

CAMARGOS, M. A.; ROMERO, J. A. R.; BARBOSA, F. V. Análise empírica da prática de insider trading em processos de fusões e aquisições recentes na economia brasileiras. Revista de Gestão USP, v. 15, n. 4, p. 55-70, 2008. Disponível em: <https://doi. org/10.5700/issn.2177-8736.rege.2008.36653>. Acesso em: 02 out. 2018.

CAVALCANTI, J. M. M.; CASTRO, S. L. Estrutura de dívidas e determinantes da estrutura de capital: uma análise das empresas do setor de bens industriais da BM\&FBovespa no período de 2009 a 2013. In: CONGRESSO UFSC DE CONTROLADORIA E FINANÇAS, 6., 2015. Anais... Santa Catarina, 2015. Disponivel em: <http://dvl.ccn.ufsc.br/congresso_internacional/anais/6CCF/61_16.pdf>. Acesso em: 07 abr. 2017.

COELHO, F. U. Curso de direito comercial. 2. ed. São Paulo: Saraiva, 2004.

COSTA, N. L. Erros e problemas na atividade de auditoria independente: uma análise dos processos da CVM. Trabalho de Conclusão de Curso (Graduação) - Faculdade de Ciências Econômicas, Universidade Federal do Rio Grande do Sul, Porto Alegre, 2012. Disponivel em: <http://www.lume.ufrgs.br/handle/10183/79380>. Acesso em: 08 abr. 2017.

CUNHA, L. F. Práticas não equitativas de mercado e sua repressão na esfera administrativa. Trabalho de Conclusão de Curso (Graduação) - Faculdade de Ciências Jurídicas e Sociais, Centro Universitário de Brasília, Brasília, 2009. Disponível em: <http:// www.repositorio.uniceub.br/bitstream/123456789/157/3/20903652.pdf>. Acesso em: 11 abr. 2017.

CUNHA, P. R.; FERNANDES, L. B.; MAGRO, C. B. D. Influência do refazimento das demonstrações contábeis no gerenciamento de resultados das empresas listadas na BM\&FBovespa. Revista de Administração, Contabilidade e Economia, v. 16, n. 1, p. 95-120, jan./abr. 2017. Disponível em: <https://editora.unoesc.edu.br/index.php/race/article/view/7305>. Acesso em: 19 abr. 2017.

CVM - Comissão de Valores Mobiliários. Instrução CVM nº 538. 2008. Dispõe sobre os processos administrativos sancionadores. Disponível em: <http://www.cvm.gov.br/legislacao/deliberacoes/deli0500/deli538.html>. Acesso em: 12 out. 2018.

CVM - Comissão de Valores Mobiliários. Instrução CVM n 545. 2014. Dispõe sobre os processos administrativos sancionadores de rito sumário. Disponível em: <http://www.cvm.gov.br/export/sites/cvm/legislacao/inst/anexos/500/inst545.pdf>. Acesso em: 18 abr. 2017.

DANTAS, J. A.; CHAVES, S. M. T.; SILVA, M. R.; CARVALHO, R. P. Determinações de refazimento/republicação de demonstrações financeiras pela CVM: o papel dos auditores independentes. Revista Universo Contábil, v. 7, n. 2, p. 45-64, 2011. Disponível em: <http://proxy.furb.br/ojs/index.php/universocontabil/article/view/2002>. Acesso em: 09 abr. 2017.

DECHOW, P. M.; GE, W.; LARSON, C. R.; SLOAN, R. G. Predicting material accounting manipulation. Working paper. 2007. Disponível em: <http://www8.gsb.columbia.edu/rtfiles/accounting/WEILIGE.pdf>. Acesso em: 03 abr. 2017.

EIZIRIK, N; GAAL, A. B.; PARENTE, F; HENRIQUES, M. F. Mercado de Capitais: Regime jurídico. Rio de Janeiro: Renovar, 2008.

FÁVERO, L. P. L.; BELFIORE, P. P.; SILVA, F. L.; CHAN, B. L. Análise de dados: modelagem multivariada para tomada de decisões. Rio de Janeiro: Elsevier, 2009.

FARIAS, R. A. S.; FREITAS, M. M de.; VICENTE, E. F. R. Insider trading: como a CVM atuou entre 2000 e 2013 para inibir essa prática? Revista Reuna, v. 20, n. 4, 27-50, 2015. Disponível em: <http://revistas.una.br/index.php/reuna/article/view/717/635>. Acesso em: 11 jan. 2018.

FONTES, R. M. Avaliação da atuação do Conselho de Administração a partir dos processos instaurados pela CVM. Dissertação de mestrado - Faculdade de Economia, Administração, Contabilidade e Ciência da Informação e Documentação, Universidade de Brasília, Brasília, 2013. Disponível em: <http://repositorio.unb.br/handle/10482/13145>. Acesso em: 13 jan. 2018.

FUSIGER, P.; SILVA, L. M da.; CARRARO, W. B. W. H. Auditoria independente: principais infrações que acarretam em processo administrativo sancionador pela Comissão de Valores Mobiliários. ConTexto, v. 15, n. 30, p. 76-93, 2015. Disponível em: <http://seer. ufrgs.br/index.php/ConTexto/article/view/52874/pdf_51>. Acesso em: 12 jan. 2018.

GIL, A. C. Métodos e técnicas de pesquisa social. 6. ed. São Paulo: Atlas, 2008. 
GIRÃO, L. F de. A. P.; MACHADO, M. R. A produção científica sobre assimetria informacional em periódicos internacionais de Contabilidade. Revista de Contabilidade \& Controladoria, v. 5, n. 1, p. 99-119, 2013. Disponível em: <http://revistas.ufpr.br/rcc/ article/view/29923/20932>. Acesso em: 15 jan. 2018

HENRIQUE, M. A. A escrituração contábil no atual cenário tributário. São Paulo: Trevisan, 2016.

IUDÍCIBUS, S.; MARION, J. C.; FARIA, A. C. Introdução à teoria da Contabilidade para o nível de graduação. 5. ed. São Paulo: Atlas, 2009.

JENSEN, M.; MECKLING, W. Theory of the firm: managerial behavior, agency costs and ownership structure. Journal of Financial Economics, v. 3, n. 4, p. 305-360, 1976. Disponível em: <https://doi.org/10.1016/0304-405X(76)90026-X>. Acesso em: 10 jan. 2018.

KOTHARI, S. P.; RAMANNA, K.; SKINNER, D. J. Implications for GAAP from an analysis of positive research in accounting. Journal of Accounting and Economics, v. 50, n. 2, p. 246-286, 2010. Disponível em: <https://doi.org/10.1016/j.jacceco.2010.09.003>. Acesso em: 09 jan. 2018.

KPMG Transaction and Forensic Services Ltda. Divulgações contábeis. 2015. Disponível em: <https://home.kpmg.com/br/ pt/home/insights/2016/11/divulgacoes-contabeis-2016.html>. Acesso em: 22 abr. 2017

LAKATOS, E. M; MARCONI, M. A. Métodos e técnicas de pesquisa. 7. ed. São Paulo. Atlas, 2008.

LISIC, L. L.; SILVERI, S. D.; SONG, Y.; WANG, K. Accounting fraud, auditing, and the role of government sanctions in China. Journal of Business Research, v. 68, n. 1, p. 1186-1195, 2015. Disponível em: <https://doi.org/10.1016/j.jbusres.2014.11.013>. Acesso em: 26 abr. 2017.

MARTINS, E.; MIRANDA, G.; DINIZ, J. Análise didática das demonstrações contábeis. São Paulo: Atlas, 2014.

MEDAUAR, O. A processualidade no Direito Administrativo. RT: São Paulo, 1993.

MELO, L.B.; ALVARENGA, F de. O.; MARQUES, J. A.V da. C.; SAUERBRONN, F. F. Qualidade da informação contábil e os processos administrativos julgados pela CVM: uma análise entre 2014 e 2016. Pensar Contábil, v. 19, n. 70, p. 24-33, 2017. Disponível em: < http://www.atena.org.br/revista/ojs-2.2.3-06/index.php/pensarcontabil/article/view/3273/2540>. Acesso em: 10 out. 2018.

MURCIA, F. D.; SANTOS, A. Fatores determinantes do nível de disclosure voluntário das companhias abertas do Brasil. Revista de Educação e Pesquisa em Contabilidade, v. 3, n. 2, p. 72-95, 2009. Disponível em: <http://www.repec.org.br/index.php/repec/ article/view/68>. Acesso em: 09 abr. 2017

OLIVEIRA, F. G. Insider trading: o comportamento da CVM e a governança corporativa das companhias abertas brasileiras. Dissertação de mestrado - Programa de Pós-Graduação em Economia, Universidade Federal do Rio Grande do Sul, Rio Grande do Sul, 2017. Disponível em: <http://www.lume.ufrgs.br/handle/10183/168634>. Acesso em: 10 jan. 2018.

PAULA, L. F.; OREIRO, J. L.; BASILIO, F. A. C. Estrutura do setor bancário e o ciclo recente da expansão do crédito: o papel dos bancos públicos federais. Nova Economia, Belo Horizonte, v. 23, n. 3, p. 473-520, 2013. Disponível em: <http://www.scielo.br/scielo. php?script=sci_arttext\&pid=S0103-63512013000300001>. Acesso em: 16 abr. 2017.

PESTANA, M. H.; GAGEIRO, J. N. Análise de dados para ciências sociais: a complementaridade do SPSS. 6. ed. Portugal: Silabo, 2014

PORTAL BRASIL. Comissão de Valores Mobiliários. 2017. Disponível em: <http://www.portalbrasil.net/cvm.htm>. Acesso em: 12 out. 2018.

SCHIPPER, K. Principles-based accounting standards. Accounting Horizons, v. 17, n. 1, p. 61-72, 2003. Disponível em: <https://doi.org/10.2308/acch.2003.17.1.61>. Acesso em: 08 jan. 2018.

SCOTT, W. R. Financial Accounting Theory. 7 ed. Toronto: Pearson, 2014.

SILVA, E. S. Mapeamento dos processos administrativos sancionadores julgados pela CVM contra os auditores independentes entre 2000 e 2014. Trabalho de conclusão de curso - Universidade de Brasília, Brasília, 2015. Disponível em: <http:// bdm.unb.br/handle/10483/13474>. Acesso em: 05 out. 2018.

SILVA, M. S.; SCHNORRENBERGER, D. Estrutura de capital e rentabilidade: um estudo sobre as empresas distribuidoras de energia elétrica listadas na BM\&FBovespa. IN: CONGRESSO BRASILEIRO DE ENGENHARIA DE PRODUÇÃO, 5. 2015. Anais... Ponta Grossa, 2015. Disponível em: <www.aprepro.org.br/conbrepro/2015/down.php?id=1313\&q=1>. Acesso em: 20 abr. 2017.

SMETANA, T. B. Os processos administrativos sancionadores julgados pela CVM e sua relação com Compliance: um estudo com as empresas listadas no índice de governança corporativa. Dissertação de mestrado - Pontifícia Universidade Católica de São Paulo, São Paulo, 2015. Disponível em: <http://www.pucsp.br/defesas/os-processos-administrativos-sancionadores-julgados-pela-cvm-e-sua-relacao-com-compliance-um-estudo-com-empresas-listadas-no-indice-de-governanca-corporativa>. Acesso em: 14 jan. 2018

SUNDFELD, C. A.; CÂMERA, J. A. Acordos substitutivos nas sanções regulatórias. Revista de Direito Público da Economia, v.9, n. 34, 2011. Disponível em: <https://edisciplinas.usp.br/pluginfile.php/234216/mod resource/content/1/Acordos $\%$ C $2 \% A-$ Osubstitutivos\%C2\%A0nas\%C2\%A0san\%C3\%A7\%C3\%B5es\%C2\%A0regulat\%C3\%B3rias.pdf>. Acesso em: 10 out. 2018.

TEIXEIRA, A. S.; POLITELO, L.; KLANN, R. C. Fatores relacionados ao refazimento das demonstrações contábeis das companhias brasileiras de capital aberto. In: ENCONTRO NACIONAL DE CURSOS DE GRADUAÇÃO EM ADMINISTRAÇÃO, 24. 2013, Florianópolis. Anais... Florianópolis/SC, ENANGRAD, 2013. Disponível em: < http://doczz.com.br/doc/613058/fatores-relacionados-ao-refazimento-das>. Acesso em: 04 abr. 2017.

ZIMMERMAN, J. L. The role of accounting in the twenty-first century firm. Accounting and Business Research, v. 45, n. 4, p. 485-509, 2015. Disponível em: <http://dx.doi.org/10.2139/ssrn.2544697>. Acesso em: 07 jan. 2018. 